\title{
Fistulas in ano: endoanal ultrasonographic assessment assists decision making for surgery
}

\author{
K I Deen, J G Williams, R Hutchinson, M R B Keighley, D Kumar
}

\begin{abstract}
Eighteen patients with a clinical impression of a complex fistula in ano, had anal endosonography to delineate the anatomy of the fistula track and identify associated areas of sepsis. The clinical impression of a complex fistula was refuted by endosonography and subsequent surgical exploration in two cases. Horseshoe tracks were identified in nine (50\%) patients and fluid collections, not evident on clinical examination were identified in eight (45\%) patients. Accurate identification of the internal opening with a $7 \mathrm{MHz}$ transducer was possible in two $(11 \%)$ cases. External sphincter damage was evident in four (22\%) patients. Surgical findings matched endosonographic appearances in all but one case (94\%). Anal endosonography is an accurate and minimally invasive method of delineating the relation of fistula tracks to the anal sphincters and identifying deep areas of sepsis in relation to such fistulas.
\end{abstract}

(Gut 1994; 35: 391-394)

Surgical treatment of a fistula in ano can be unrewarding because of recurrence ${ }^{1-3}$ and the development of faecal incontinence as a result of iatrogenic injury or anal sphincter damage by chronic sepsis. ${ }^{+6}$ To minimise the incidence of these complications, a method of delineating the anatomy of the fistula track will complement clinical assessment and examination under anaesthesia by an experienced surgeon and possibly help in the choice of treatment - that is, excision of fistula track, seton drainage or a combination of the two.? course of fistula tracks. Goodsall's rule has been reported to vary in accuracy..$^{8-10}$ Fistulography, on the other hand, has been wholly disappointing. " More recently, anal endosonography has been shown to define the nature of the anal sphincters and permit the identification of perianal sepsis with accuracy. ${ }^{12}$ This study reports on our experience with the use of ultrasound to assist in the surgical treatment of fistulas in ano.

Department of Surgery, Queen Elizabeth Hospital, Birmingham K I Deen

J G Williams

R Hutchinson

M R B Keighley

D Kumar

Correspondence to: Mr D Kumar, Consultant Senior Lecturer, Queen Elizabeth Hospital, Edizabeth Hospital, B15 2TH.

B15 2TH. 26 July 1993

\section{Patients and clinical assessment}

Eighteen patients (12 male: 6 female; age range 23 to 67 years, median age 41 ), referred to this institution over a period of 16 months, for assessment and treatment of fistulas in ano were either cases of recurrent or non-healing fistula in These patients were assessed by clinical history and digital examination, anal endosonography and finally, examination under anaesthesia. Pre-
Various methods have been used to predict the

operative clinical assessment and subsequent surgical treatment was performed by either a consultant surgeon or senior registrar.

Clinical examination included assessment of induration and scarring in the perianal region, external and internal openings, and whether the fistula affected the anal sphincters. An attempt was also made to identify the presence of horseshoe tracks. Three patients were known cases of Crohn's disease. None was diabetic.

\section{ANAL ENDOSONOGRAPHY}

The examination was performed with a $7 \mathrm{MHz}$ rotary transducer enclosed within a water filled sonolucent cone with a penetration of between 2-5 cm (Bruel and Kjaer, UK Ltd, Harrow, Middlesex). It was performed in the left lateral position without prior preparation of the anorectum. Assessments were made at upper, middle, and lower anal canal and images were obtained on a thermal printer (Imotek Ltd, Cambridge) for later interpretation and comparison with postoperative images. Specific features sought were (a) site of internal opening, (b) level of radial track, (c) relation of tracks to anal sphincters - that is, intersphincteric, transphincteric or extrasphincteric, (d) site of fluid collections. In all cases, endosonography was performed at the lower magnification and further detail, such as the site of an internal opening, then visualised at a higher magnification.

\section{OPERATIVE ASSESSMENT}

All patients were assessed in the lithotomy or prone jacknife position depending on the surgeon's preference. Examinations were performed under general anaesthetic. The site of external and internal opening(s), number of identified fistula tracks, areas of fluid collections were recorded for comparison with ultrasound findings. Finally, the surgeon was also asked if anal endosonography was helpful in the overall assessment of the fistula in ano.

\section{Results} ano after previous attempts at curative surgery.

Preoperative clinical assessment showed induration of the skin in the perianal region in all patients. Despite this clinical examination failed to accurately localise the site of fluid collection. There were a total of 24 external openings (six with more than one external opening) identified but only nine internal openings were identified during outpatient clinic assessment. A horseshoe connection was suspected in three patients and 
Comparison: clinical and operative $\mathrm{v}$ ultrasound (US)

\begin{tabular}{lcclc}
\hline Component & $\begin{array}{l}\text { Clinicall } \\
\text { operative }\end{array}$ & $\begin{array}{l}\text { US } \\
\text { correct }\end{array}$ & $\begin{array}{l}\text { US } \\
\text { incorrect }\end{array}$ & Accuracy \\
\hline Internal opening & 20 & 2 & 0 & $10 \%$ \\
Horseshoe & 11 & 10 & $1^{\star}$ & $91 \%$ \\
Fluid collection & 8 & 8 & 0 & $100 \%$ \\
Tracks & 37 & 37 & 0 & $100 \%$ \\
\hline
\end{tabular}

*Ultrasound failed to identify.

$\star \star 14 / 18(78 \%)$, complex; 4/18 (22\%). simple.

later confirmed by ultrasound and operative assessment. All fistulas were found to extend into or above the anal sphincters (high fistulas) and were thus unsuitable for primary treatment by fistula excision or incision alone. All 18 patients showed perianal scarring, indicative of previous fistula surgery.

\section{ANAL ENDOSONOGRAPHY}

Anal endosonography showed 14 complex fistulas, where two or more tracks were present in different planes. Four simple fistula tracks were also identified. Findings were confirmed at operation (Table). In two patients, the clinical impression of a complex fistula was refuted by ultrasound and subsequent surgical exploration.

Horseshoe complications, in 10 patients (56\%), were the commonest endosonic finding (Fig 1). In one case, there were two horseshoe communications, one in the lower and another in the upper anal canal. One horseshoe track at the anal verge was not identified by ultrasound.

Fluid collections (pus or seropurulent fluid) identified in eight patients (45\%), were the second commonest finding (Figs 2 and 3). Four of these collections were contralateral to the site of the external opening. All collections were deep seated in the ischiorectal fossa in the region of the upper anal canal. Furthermore, two of these collections also had supralevator extensions, identified by ultrasound and confirmed by surgical exploration.

Accurate identification of the internal opening was possible by ultrasound in only two patients (Fig 4).

Damage to the external anal sphincter, evidenced by loss of mixed echogenicity in comparison with this sphincter muscle at

Figure 1: Anal endosonography at mid anal canal level in a 56 year old man showing a posterior intersphincteric horseshoe fistula (hypoechoic area marked $h$ with arrows showing the limit of fistula track).

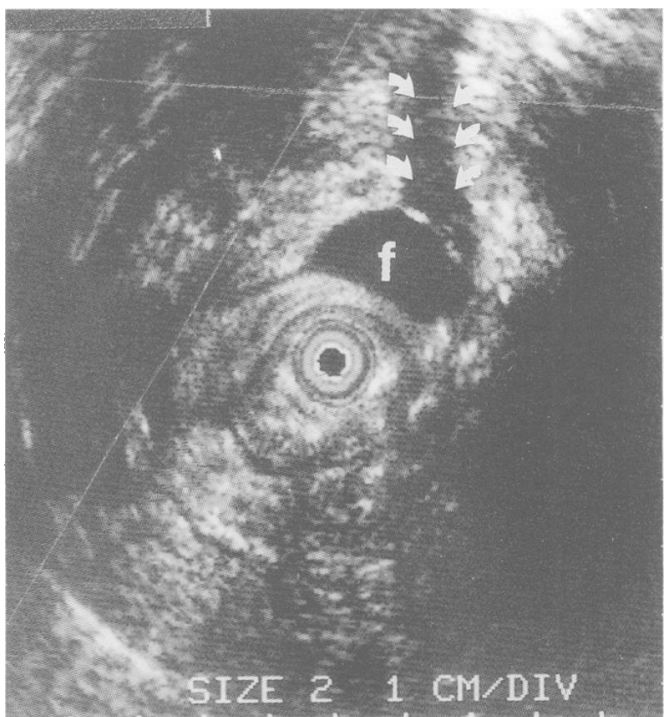

Figure 2: Right sided fluid collection $f$, showing a

characteristic acoustic shadow (arrows).

another level of the anal canal, was seen in four patients (Fig 5). Findings on anal endosonography matched operative findings in all but one case $(95 \%)$. The surgeon considered previous knowledge of fistula anatomy helpful in 16 of 18 cases $(89 \%)$. In the two where anal endosonography did not contribute, a single intersphincteric fistula track was encountered in each case.

\section{OPERATIVE ASSESSMENT}

Examination under anaesthesia, showed 20 internal openings, 11 horseshoe fistulas, and a total of 37 fistula tracks. Although the perianal region was inflamed, there was no evidence of pointing in the perianal skin or anorectal mucosa, which suggested the presence of a fluid collection.

\section{Discussion}

This study confirms the findings of other

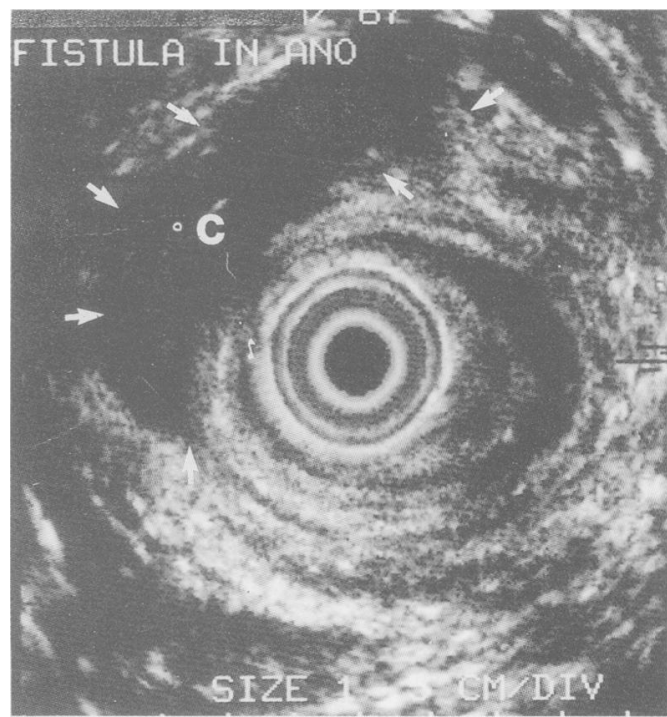

Figure 3: Postero right lateral collection ( $c$ - extent shown by arrows) in a 42 year old man with a recurrent fistula in ano. The collection was confirmed to be pus in the infralevetaor region at operation. 


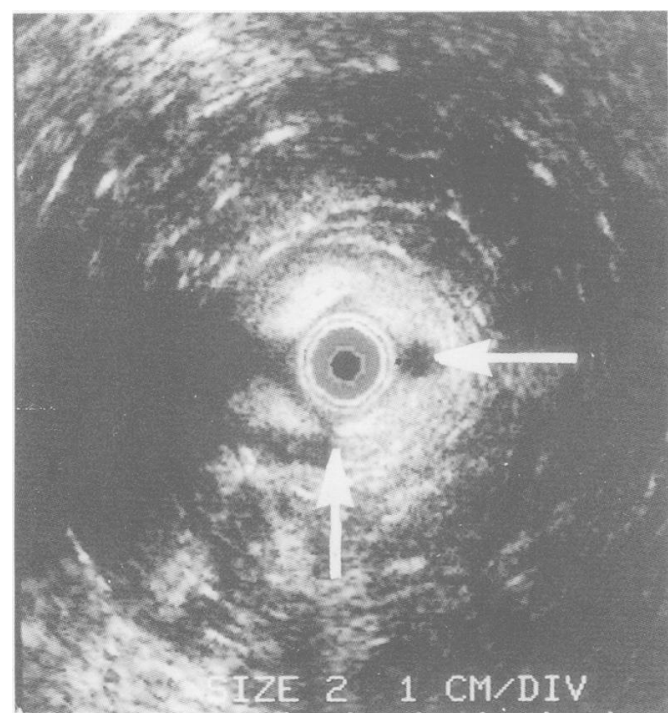

Figure 4: Two internal openings (arrows) in the mid anal canal.

workers who have shown that anal endosonography is useful in identifying the anatomy of complex fistulas in ano. ${ }^{12}$ In addition, we have shown that complex fistula tracks with horseshoe connections or purulent collections, or both are commonly associated with recurrent fistulas in ano. In a few patients, however, recurrent symptoms may arise from a simple - that is, a single track, fistula.

Deep seated collections can be difficult to locate even during an examination under anaesthesia, where scar tissue or induration from previous surgery and concurrent inflammation can mask such collections, which do not possess external manifestations such as pointing. Indeed, anal endosonography was not only helpful in identifying the latter but also provided useful evidence of a supralevator extension of such collections, where irregular hypoechoic areas at the level of puborectalis were seen to continue in a cephalad direction until acoustic contact was finally lost in the lower rectum.

Identification of the internal opening continues to pose problems for anal endosonography using a $7 \mathrm{MHz}$ transducer with image magnification. There is little doubt, however, that this will be overcome by the use of higher frequency transducers, which possess superior near image quality. ${ }^{13}$ Identification of internal openings by ultrasound in this study was poor and differed considerably from those of Choen et al. The most probable reason for this were the criteria used in ultrasound diagnosis of an internal opening. While a breach of the mucosa was considered the only feature by which an internal opening was diagnosed in this study, Choen et $a l^{14}$ used several secondary features, such as a defect in the circular or longitudinal muscles of the anal canal to make such a diagnosis. In our experience, hypoechoic areas amid the circular and longitudinal muscle layers were often confused with fistula tracks.

Another area in which ultrasound was unhelpful was at the anal verge, where a horseshoe communication was missed. In retrospect, this was because of misinterpretation but other workers have also reported poor imaging quality

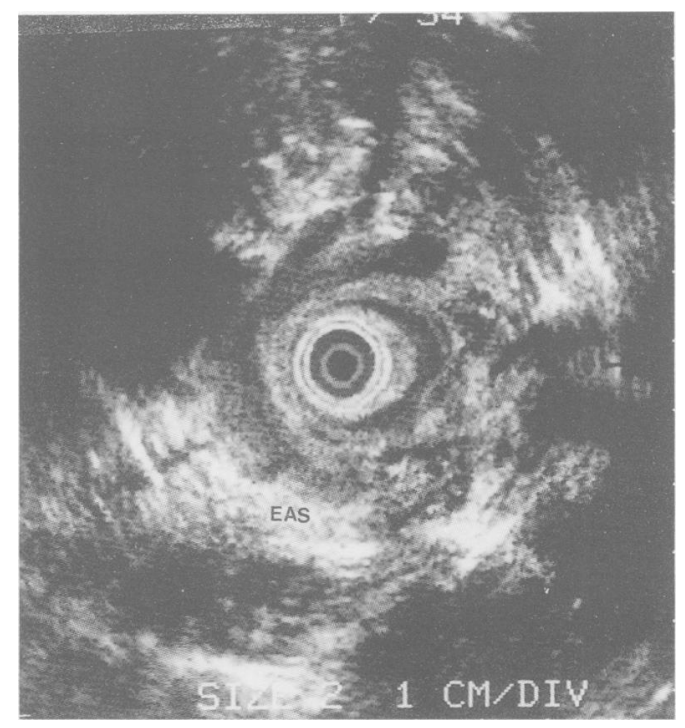

Figure 5: Circumferential external anal sphincter (EAS) destruction (loss of mixed echogenicity) caused by sepsis.

of anal endosonography at this level, particularly of submucosal fistula tracks. ${ }^{14}$

Septic damage to external anal sphincter was seen in four patients. Although Law $e t a l^{12}$ point out that interpretation of sphincter destruction may not be accurate because of acoustic shadow arising from inflammation or fluid collection, we found these changes throughout the circumference of the sphincter muscle. This is more probably a result of sphincter damage. While endoanal ultrasound has been found to be useful for assessing fistulas in ano in this and other studies, it should not be considered an alternative to a thorough clinical evaluation in these patients. Indeed, the experienced clinician can identify the components of a fistula track with a high degree of accuracy. ${ }^{14}$

Anal endosonography is a useful investigation that complements preoperative clinical assessment of fistulas in ano by providing clear anatomical detail of the fistula track in relation to the anal sphincters. The mobility of the apparatus permits endosonic assessment of fistulas in the operating theatre. This could help minimise sphincter damage particularly with the less experienced surgeon, by aiding the choice of surgical treatment. A fistula track affecting minimal muscle can be safely excised but, where the bulk of external sphincter muscle is affected, it is best treated by seton drainage followed by seton fistulotomy. In the absence of underlying pathology such as Crohn's disease or diabetes mellitus, complex horseshoe communications together with occult collections of purulent fluid identified by ultrasound, were the main features associated with recurrence.

This study was supported by the Medical Research Council.

1 Parks AG, Stitz RW. The treatment of high fistula-in-ano. Dis Colon Rectum 1976; 19: 487-99.

2 Kuypers AC. Use of the seton in the treatment of extra sphincteric anal fistula. Dis Colon Rectum 1984; 27 : 109-10.

3 Hanley PH, Ray JE, Pennington EE, Grablowsky OM. Fistula-in-ano: a ten year follow up study of horseshoe abscess fistula-in-ano. Dis Colon Rectum 1976; 19: 507-15.

4 Sainio P, Husa A. Fistula-in-ano: clinical features and term results in 199 adults. Acta Chir Scand 1985; 151: 169 76.

5 Kennedy HL, Zegara JP. Fistulotomy without external sphincter division for high anal fistulae. Br $\mathcal{F}$ Surg 1990; 77: 898-901. 
6 Schouten WR, VanVroonhoven TJMV. Treatment of anorectal abscess with or without fistulotomy: results of a prospective randomised trial. Dis Colon Rectum 1991; 34: 60-3.

7 Williams JG, Rothenberger DA, Nemer FD, Goldberg SM Fistula-in-ano in Crohn's disease: results of aggressive surgical treatment. Dis Colon Rectum 1991; 34: 378-84.

8 Cirocco WC, Reilly JC. Challenging the predictive accuracy of Goodsall's rule for anal fistulas. Dis Colon Rectum 1992; 35 : $537-42$.

9 Rankin FW, Bargen JA, Buie LA. The colon, rectum and anus. Philadelphia: WB Saunders, 1932: 593-602.

10 Hiller RI. Anal sphincter and pathogenesis of anal fistula and fissure. Surg Gynecol Obstet 1931; 52: 921 .
11 Corman ML. Anorectal abscess and fistula. In: Corman ML, ed. Colon and rectal surgery. 2nd ed. Philadelphia: JB Lippincott. 125-70.

12 Law PJ, Talbot RW, Bartram CI, Northover JMA. Anal endosonography in the evaluation of perianal sepsis and fistula-in-ano. Brf Surg 1989; 76: 752-5.

13 Miller L, Alexander A, Liu JB, Feld R, Goldberg B. High frequency endoluminal ultrasound of the anal canal Gastroenterology 1992; 102: A486.

14 Choen S, Burnett S, Bartram CI, Nicholls RJ. Comparison between anal endosonography and digital examination in the evaluation of anal fistulae. Br f Surg 1991; 78: in the 7 . 